\title{
Ruptured Valsalva Sinus Aneurysm with Ventricular Septal Defect and Double- Chambered Right Ventricle without Heart Failure: A Case Report
}

\author{
Keito Suzuki, MD, Akira Sezai, MD, PhD, Rei Hinoura, MD, Satoshi Unosawa MD, PhD, Masashi Tanaka, \\ $\mathrm{MD}, \mathrm{PhD}$
}

Department of Cardiovascular Surgery, Nihon University School of Medicine, Tokyo, Japan

\section{ABSTRACT}

Valsalva sinus aneurysm and double-chambered right ventricle are both rare congenital cardiac anomalies. Ventricular septal defect may be present in approximately 50\%-60\% of patients with Valsalva sinus aneurysm or approximately $70 \%-80 \%$ of patients with double-chambered right ventricle. However, Valsalva sinus aneurysm, double-chambered right ventricle, and ventricular septal defect rarely coexist in the same patient. As these diseases progress, patients often complain of symptoms of heart failure, due to the shunt flow. The case of a patient with Valsalva sinus aneurysm, doublechambered right ventricle, and ventricular septal defect without symptoms of heart failure had never been reported until now.

\section{INTRODUCTION}

Valsalva sinus aneurysm, a rare anomaly, typically is congenital and associated with ventricular septal defect (VSD), but is sometimes acquired, associated with an infectious process, such as endocarditis or syphilis. An unruptured aneurysm is difficult to diagnose, although once ruptured, it often produces hemodynamic instability, and patients complain of symptoms of heart failure, such as dyspnea. Double-chambered right ventricle also is a rare congenital anomaly associated with VSD. A hypertrophied moderator band or accentuated septoparietal trabeculation divides the right ventricle into two chambers. However, to our knowledge, these three disorders, namely Valsalva sinus aneurysm, double-chambered right ventricle, and VSD, have not been reported in the same case. This report describes a case of these diseases occurring at the same time in a 51-year-old woman. She had no complaints of heart failure, despite the ruptured Valsalva sinus aneurysm, double-chambered right ventricle, and VSD.

Received March 16, 2019; received in revised form fuly 29, 2019; accepted August 16, 2019.

Correspondence: Masashi Tanaka, MD, PbD, Department of Cardiovascular Surgery, Nihon University School of Medicine, 30-1 Oyaguchi-kamimachi Itabashi-ku Tokyo, 173-8610, Japan; 81-3-3972-8111; fax: 81-3-39559818 (e-mail: tanaka.masasbi@nibon-u.ac.jp).

\section{CASE REPORT}

A 51-year-old woman with a known congenital ventricular septal defect presented to the hospital with a fever, due to a common cold. On exam, she was found to have a cardiac murmur, and echocardiography revealed a ruptured Valsalva sinus aneurysm. Thus, she was referred to our hospital for surgical repair.

Transthoracic echocardiography revealed normal left ventricular cavity dimensions with normal wall thickness and function. The thick wall and constriction of the lumen in the middle of the right ventricle was revealed, where the flow rate was increased to $>3.5 \mathrm{~m} / \mathrm{sec}$. This indicated a diagnosis of double-chambered right ventricle. Color Doppler images showed a shunt flow from the right coronary cusp to the right ventricle. VSD shunt was not evident. Transesophageal echocardiography revealed a VSD type 1 where a shunt flow was confirmed at the systole, whereas continuous shunt flow of the ruptured Valsalva sinus aneurysm was confirmed. Qp/ Qs was 2.56, but was not correctly measured because of the mixed flow. A computed tomography scan confirmed the inflow of contrast from the Valsalva sinus into the right ventricle. Right heart catheterization revealed an increase in oxygen saturation from $75 \%$ in the right ventricle to $90 \%$

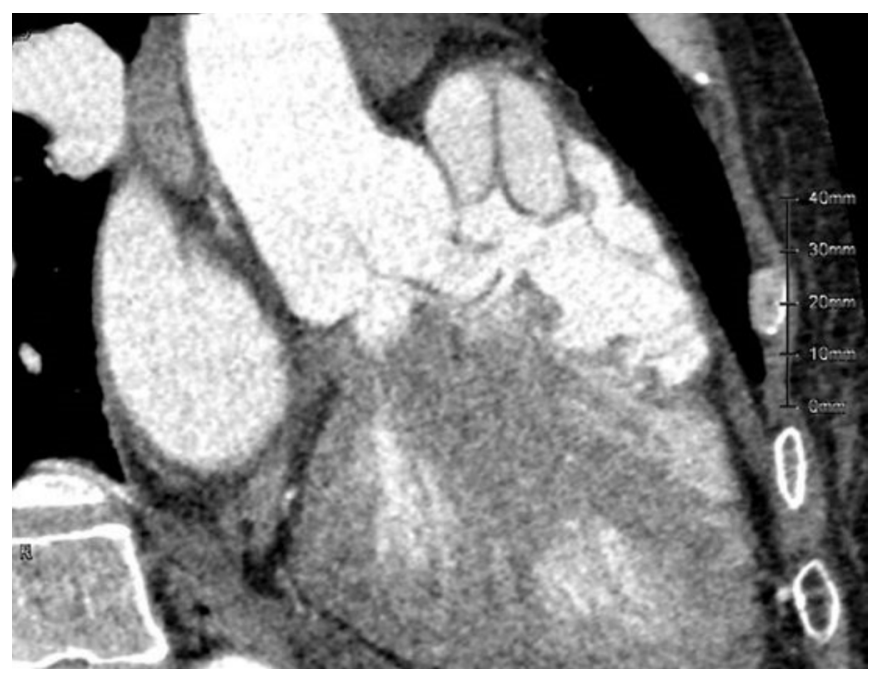

Figure 1. Computed tomography showing the flow from the right coronary sinus to right ventricle. 


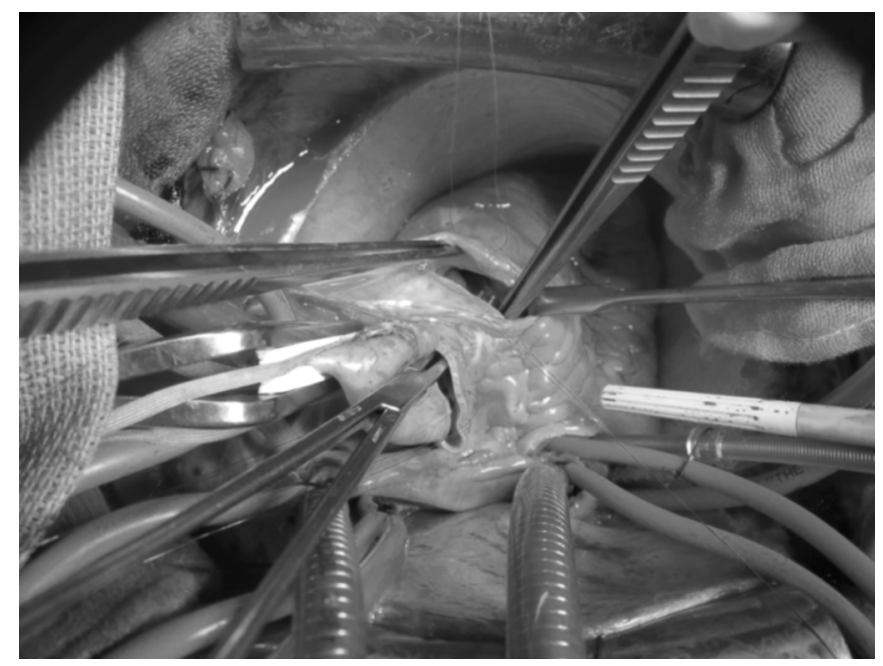

Figure 2. A, Ruptured Valsalva sinus aneurysm into the right ventricle.

in the pulmonary artery. The peak systolic pressure gradient between the inflow and outflow portions of the right ventricle was $49 \mathrm{~mm} \mathrm{Hg}$. The contrast showed a stenosis of the right ventricular outflow tract. The coronary arteriography result was normal, but a shunt flow from the right coronary cusp to the right ventricle was observed.

At surgery, the right ventricle and pulmonary artery were enlarged. A cardiopulmonary bypass was established via the ascending aorta, and superior and inferior vena cava. After aortic cross-clamping and cardioplegic arrest, an abnormal myocardial bundle in the right ventricle, which caused a double-chambered right ventricle, was resected through the pulmonary valve. There was a ruptured hole just below the pulmonary valve connected from the right coronary cusp. The VSD was located below the hole. The VSD was closed with a bovine pericardium patch, and then closed the hole of the ruptured Valsalva sinus aneurysm directly through the pulmonary valve. Furthermore, the hole with the bovine pericardium patch was closed through the transverse aortotomy. The operation time was 188 minutes. The aortic clamping time was 101 minutes. The cardiopulmonary bypass time was 118 minutes. The postoperative course was good, and echocardiography revealed no shunt flow. She was discharged on the 13 th postoperative day.

\section{DISCUSSION}

Valsalva sinus aneurysm is congenital or associated with an infectious process, such as endocarditis or syphilis. In the former instance, $50 \%-60 \%$ of patients have a history of VSD [Jung 2008; Moustafa 2007; Post 2010; Miranda 2005]. It sometimes is caused by a hemodynamic effect (Bernoulli effect) associated with the shunt flow [Maruo 2003]. Males are more frequently affected than females. The right sinus is the most common site of Valsalva sinus aneurysms, followed by the noncoronary sinus [Miranda 2005]. The fistulous tract of ruptured Valsalva sinus aneurysms is frequently formed

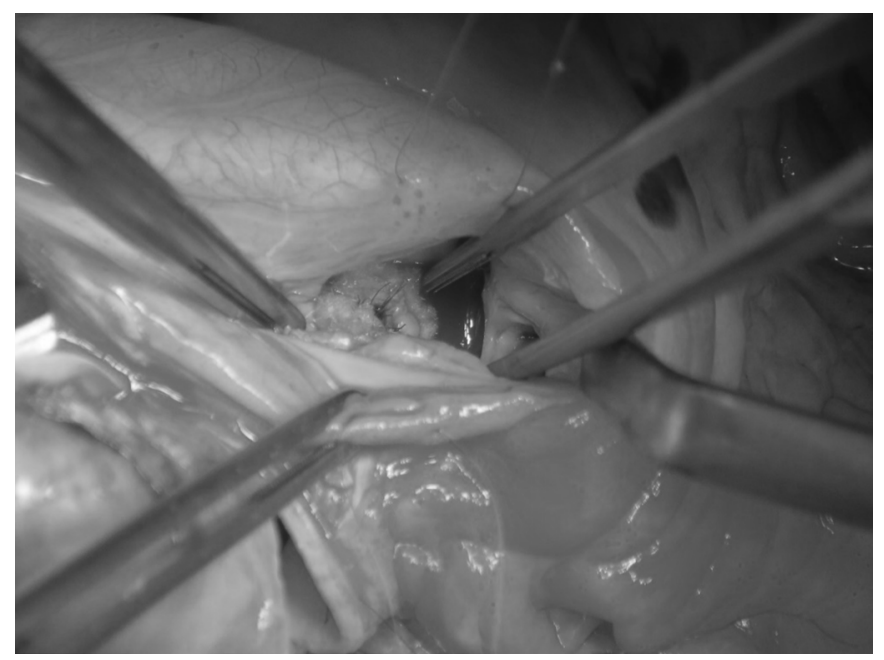

Figure 2. B, Ruptured Valsalva sinus aneurysm closed directly through the pulmonary valve.

in the right ventricle or right atrium. Rupture into the pulmonary artery is rare [Jung 2008; Moustafa 2007; Post 2010; Miranda 2005; Takach 1999; Maruo 2003]. In cases of unruptured aneurysms, patients have no complaints and typically are diagnosed by chance. On the other hand, once aneurysms rupture, patients often show symptoms of heart failure caused by the shunt flow. Surgical indication for asymptomatic Valsalva sinus aneurysm has not been established; however, early treatment is necessary for ruptured cases because of the reported average prognosis of 3.9 years [Post 2010; Miranda 2005; Takach 1999].

A double-chambered right ventricle also is a rare congenital anomaly. Among all patients, $70 \%-80 \%$ have a history of VSD [Galal 2000; Cabrera 1995]. A hypertrophied moderator band or accentuated septoparietal trabeculation divides the right ventricle into two chambers. While the pressure on the pulmonary artery side decreases, pressure on the tricuspid valve side increases. Differences in these pressures may cause heart failure, and patients sometimes complain of sudden dyspnea. Thus, surgical treatment is necessary. While the surgical outcome in children is reported to be good [Gallucci 1980], that in adults is unclear. Although betablockers have been reported to be useful for treatment [Arai 2001], the only established therapy is the surgical removal of anomalous muscle bundles.

In our case, ruptured Valsalva sinus aneurysm, doublechambered right ventricle with a $49 \mathrm{mmHg}$ pressure gradient, and ventricular septal defect with a Qp/Qs of 2.56 was diagnosed. Nevertheless, the patient had no symptoms. Our findings suggest that she did not have any complaints because both apertures of the ruptured Valsalva sinus aneurysm and ventricular septal defect were open to the outflow tract of the right ventricle, where the pressure was low due to the doublechambered right ventricle.

In summary, this patient had three congenital disorders: ruptured Valsalva sinus aneurysm, double-chambered right ventricle, and ventricular septal defect. Although 
the patient did not experience heart failure, heart failure seemed to develop soon due to the right heart overload. The diagnosis was confirmed using echocardiography and catheterization. Successful treatment was achieved by surgical intervention.

\section{REFERENCES}

Arai N, Matsumoto A, Nishikawa N, et al. 2001. Beta-blocker therapy improved symptoms and exercise capacity in a patient with dynamic intra-right ventricle. J Am Soc Echocardiogr 14:650-653.

Cabrera A, Martinez P, Rumoroso JR, et al. 1995. Double-chambered right ventricle. Eur Heart J 16:682-686.

Galal D, Al-Halees Z, SOlymer L, et al. 2000. Double-chambered right ventricle in 73 patients: Spectrum of the disease and surgical results of transatrial repair. Can J Cradiol 16:157-174.

Gallucci V, Scalia D, Thiene G, et al. 1980. Double-chambered right ventricle: Surgical Experience and Anatomical Considerations. Thorac Cardiovasc Surg 28:13-17.
Jung SH, Yun TJ, Im YM, et al. 2008. Ruptured sinus of Valsalva aneurysm: transaortic repair may cause sinus of Valsalva distortion and aortic regurgitation. J Thorac Cardiovasc Surg 135:1153-1158.

Maruo A, Higami T, Obo H, Shida T. 2003. Ruptured sinus of Valsalva aneurysm associated with aortic regurgitation caused by hemodynamic effect solely. Eur J Cardiothorac Surg 24:318-319.

Miranda D, Peter AA, Osorio J, Ferreira AC. 2005. Ruptured Aneurysm of the Noncoronary Sinus of Valsalva. Tex Heart Inst J 32:586-588.

Moustafa S, Mookadam F, Cooper L, et al. 2007. Sinus of Valsalva aneurysms -47 years of a single center experience and systematic overview of published reports. Am J Cardiol 84:156-160.

Post MC. Braam RL, Groenemejier BE, et al. 2010. Rupture of right coronary sinus of Valsalva aneurysm into right ventricle. Neth Heart J 18:209-211.

Takach TJ, Reul GJ, Duncan JM, et al. 1999. Sinus of Valsalva Aneurysm or Fistula: Management and Outcome. Ann Thorac Surg 68:1573-1577. 